\begin{tabular}{l|l} 
Investigaciones & $\begin{array}{l}\text { Revista Colombiana } \\
\text { de Educación, N. 63. } \\
\text { Segundo semestre de 2012, } \\
\text { Bogotá, Colombia. }\end{array}$
\end{tabular}

\title{
Nueve experiencias desde el cine: un \\ pretexto para ampliar el campo de visión \\ en la investigación*
}

//Nine movie-experiences: A pretext

to expand focus on research

//Nove experiências a partir do cinema:

um pretexto para ampliar o campo de

visão na investigação

Harold Viafara Sandoval ${ }^{* *}$

\begin{abstract}
El presente escrito es el producto del trabajo realizado durante el Seminario "Pedagogía, Escuela y Cine" a cargo del Ph.D. Alberto Martínez Boom, del Doctorado Interinstitucional en Educación, Universidad Pedagógica Nacional, Universidad Distrital Francisco José de Caldas y Universidad del Valle. Bogotá, Colombia, Suramérica, Semestre 2011-1. Doctorando en Educación, convenio Universidad Pedagógica Nacional, Universidad del Valle y Universidad Distrital Francisco José de Caldas. Profesor asociado de la Facultad de Educación, Universidad de San Buenaventura Cali. Correo electrónico: hviafara@usbcali.edu.co - harvisa@hotmail.com - Colombia.
\end{abstract}

\section{Resumen}

Este artículo da cuenta de una reflexión que, teniendo como punto de partida las discusiones sobre educación, pedagogía y estética, recurre al cine con una postura distante de este como recurso de enseñanza o mediación didáctica y acudiendo a cierta perspectiva para abrir la mirada y pensar problemas propios de la investigación. Aquí se vuelve al cine como experiencia artística y sensible, en la idea de generar una especie de ruido alrededor de la propuesta de investigación titulada preliminarmente "Cuerpo, consumos y educación: tres dimensiones para proponer un debate teórico". Consecuente con un ejercicio de artesanía intelectual e investigativa, implicaba ampliar el campo de visión con lo cual se intentaba permanentemente mantener dos esfuerzos: romper los límites de los análisis a los que hemos estado acostumbrados y problematizar el objeto de estudio desde una dimensión teórica. Para ello, el pretexto empírico da cuenta de un recorrido por nueve películas, a partir de las cuales se mantuvo una alerta inevitable. Por eso un despliegue al análisis de las dimensiones analíticas que esto concita conllevó si bien a una pregunta por el sujeto, igualmente a valorar la construcción de la noción de cuerpo que ellas abordaban.

En tal sentido, en el artículo se recurre metodologicamente a recrear de manera breve este grupo de películas a través de las cuales estuvo siempre presente un interrogante explícito y en algunos casos implícito: ¿Cuál es la noción de cuerpo que en ellas subyace y sus implicaciones para pensar el objeto: cuerpo, consumos y educación?

\section{Abstract}

This paper offers a reflection based on some discussions as starting point focused on education, pedagogy and aesthetics. Movies represent a distant position to analyze as a teaching resource or didactics to open new doors and think own research issues. Here movies become a sensitive and artistic experience to generate a new preliminary research proposal entitled "Body, consumption and education: a three-dimension proposal to a theoretical debate."

Consistent to an intellectual and research exercise involves expanding focus which is constantly trying to keep two efforts: first, pushing limits of analysis we have been used, and second, problematizing the study object from a theoretical dimension. In this regard we recreate methodologically a group of nine films through which a question has been always asked, explicit and sometimes implicit: What is the underlying notion of body and its implications for thinking a subject: body, consumption and education?

\section{Palabras Clave}

Cuerpo, consumos educación, cine, investigación.

\section{Keywords}

Body, consumption, education, movies, research.

\section{Palavras chave}

Corpo, educação, consumo, cinema, pesquisa. 


\section{Resumo}

O artigo dá conta de uma reflexão que, tendo como ponto de partida as discussões sobre educação, pedagogia e estética, recorre ao cinema com uma postura distante de sua consideração como um recurso para ensinar ou como mediação didática, concorrendo em certa perspectiva para abrir o olhar e pensar problemas próprios da investigação. Aqui se torna ao cinema como uma experiência artística e sensível, com a idéia de gerar uma espécie de ruído em torno da proposta de investigação intitulada preliminarmente "Corpo, consumos e educação: três dimensões para propor um debate teórico". De forma consequente com um exercício de artesania intelectual e investigativa, implicava ampliar o campo de visão com o qual se tentava permanentemente manter dois esforços: romper os limites das análises a que fomos acostumados e problematizar o objeto de estudo a partir de uma dimensão teórica. Para isto, o pretexto empírico dá conta da passagem por nove 9 filmes a partir dos quais se manteve um alerta inevitável. Por isso, uma separação em relação à análise das dimensões analíticas que isto provoca levou a uma pergunta sobre o sujeito, bem como a valorar a construção da noção de corpo que elas abordavam. Nesse sentido, no artigo se recorre metodologicamente à recriação, de maneira rápida, desse grupo de filmes, através dos quais esteve sempre presente um questionamento explícito e em alguns casos implícito: qual é a noção de corpo que nelas subjaz e suas implicações para pensar o objeto corpo, consumo e educação?

\section{Entrando}

Había estado acostumbrado a mirar el cine por allá como lo aprendí a mediados de la década del setenta del siglo pasado cuando aún la adolescencia estaba construyendo sus frutos-; en aquel entonces era imprescindible dejarse atrapar por la historia del superhéroe; casi imposible de renunciar a reírse por los logros de la comedia; no era fácil escaparse a la posibilidad de dejar salir algunas lágrimas por un desenlace de las clásicas y románticas historias mexicanas; resultaba casi impostergable el querer ser como el gran vaquero. Pero aquí no estaba frente a la superpantalla que tenía de chico, donde pagaba por una película y me daban tres, El Vargas, aquellos lugares en los cuales siempre estuve acompañado por los amigos y amigas de adolescencia; ya no me encontraba en el María Luisa, tampoco en el México, menos en el San Nicolás, y por qué no decir que mucho menos en el Imperio, no era en el Calima, creo que tampoco en el San Fernando, o El Bolívar, en fi n, no era ninguno de esos teatros de la querida Cali, Colombia, vale decir, ya no habitaba las salas de cine de mi infancia, de aquella ciudad donde siempre me dijeron que las caleñas eran como las flores. Estaba en otro lugar. 


\section{Sin querer salir}

En mi pueblo, cuando eramos niños, mi madre nos preguntaba a mi hermano y a mí si preferíamos ir al cine o a comer con una frase festiva: "¿Cine o sardina?". Nunca escogimos la sardina. (Guillermo Cabrera Infante - "Cine o sardina").

Optar por el cine en esta oportunidad antes que eso, es sobre todo la entrada a un escenario del cual no se quiere salir, pues más allá de la seducción que propone el Ilamado séptimo arte y la construcción de una experiencia sensible, configura uno de los primeros quiebres, el cine: distante de su sentido a la manera de recurso didáctico, para potenciar pensamiento investigativo. Un segundo quiebre sugiere otro elemento: la discusión en relación con la educación y la pedagogía y sus posibilidades desde la investigación en el mundo estético. Da cuenta de un elemento central el tercero, pues sugiere un plano de configuración de distanciamiento. Un cuarto quiebre alude a una renuncia a diversos cánones del Ilamado: sentido lineal, del contexto y de la unilinealidad en la forma de relacionar un hecho con otro, es una convocatoria a pensar distinto.

\section{Para ampliar el campo de visión}

A través de las diferentes películas, es factible señalar aquellos aspectos que Ilenan de contenido la siguiente pregunta: ¿Es posible ampliar con el cine el campo de visión, para problematizar problemas de investigación?

Allí bien cabe iniciar con el film Blow Up, pues el contrasta la relación tiempo - velocidad vs. tiempo - realidad.

"Es un film íntimamente ligado al tiempo en el que fue hecho: Londres, a mediados de los 60, basado en un cuento de Julio Cortázar que cuestiona el poder de la veracidad de la imagen a través de la historia de un fotógrafo que asegura poder resolver el enigma de un crimen, a partir del análisis de una serie de fotografías que él había realizado y que amplía en sucesivos "blow-ups". Adaptación del relato "Las babas del diablo" de Julio Cortázar, que cuenta la historia de Roberto Michel, un traductor chileno que vive en París. Aficionado a la fotografía, un domingo fotografía a una mujer que besa a un adolescente. La mujer le pide el carrete enfadada, al momento un hombre de sombrero gris se une a la mujer en la petición. Michel se alegra de que el chico haya logrado abandonar el lugar. Pero, cuando amplía las fotografías en casa, imagina 
que las imágenes cobran movimiento y que el chico no ha logrado escapar. El fotógrafo acaba mirando al cielo con impotencia a través de un "rectángulo clavado con chinchetas en la pared de su habitación". La historia de Blow Up parte del relato de Cortázar, de quien Antonioni toma sólo la idea: un fotógrafo profesional descubre al revelar y ampliar un carrete de fotografías algo que a simple vista no había sido capaz de ver".

Tal vez, desde esta dimensión la película intenta llamar la atención sobre las formas de abordar el conocimiento de la realidad, rastreando: los hechos, hallazgos, sus rasgos, las discontinuidades, etc. En otro sentido, tomando como referente elementos de la perspectiva foucaultiana, la película recrea el panóptico a partir de una triple interacción: cuerpo/miradas/poder. Aquí, la perspectiva del control asumida por un fotógrafo es bastante significativa: él lo controla todo; por ello cuando algo no le es posible controlarlo -sensación de discontinuidad- se le pierde el referente. Además se hace dueño de un saber del cual no tienen conocimiento otros, y esto lo constituye en un sujeto particular. La película pone en crisis el canon institucional en tanto se mofa de él, lográndolo a partir de unos cuadros muy precisos: las escenas de las monjas, la rutina del policía, la fuerza de los mimos, etc.

Blow Up, con la experiencia fotográfica ubica la(s) mirada(s) en una perspectiva de zoom y rezoom ${ }^{1}$, vale decir, como la observación al adentro y desde el adentro, no siendo formas antagónicas, por el contrario, en la idea de estrategias complementarias. El film permite pensar una "mirada comprensiva", o sea aquella que garantiza cierta opción analítica amplia de la realidad investigada, donde el abordaje no siempre se sitúa en el interior mismo de esa realidad, sino en los bordes, a partir del afuera.

En este film, los diálogos de la película gozan de una lentitud particular, podría decirse entonces que el espacio entre imágenes da cuenta de una posibilidad sui géneris para pensar y revalorar la noción de velocidad propuesta por Virilio (1997a). Allí lo que podría enunciarse es la clara manera de dos formas de ver el mundo: una primera da cuenta de la persistencia del 
ojo humano y otra de la persistencia del uso del objeto. Puede señalarse, entonces, que Blow Up como la máxima ampliación del objeto, muestra finalmente la forma en que una ampliación exagerada termina con la destrucción del objeto.

La noción de velocidad es una cuestión primordial para forma parte del problema de la economía en la idea de argumento teórico. La velocidad es, a su vez, una amenaza tiránica, según el grado de importancia que se le dé, y, al mismo tiempo, ella es la vida misma. No se puede separar la velocidad de la riqueza. (Virilio, 1997a, p. 16).

Ahora, la pregunta que da origen al film ¿Dónde está la casa de mi amigo?, arrastra una sentencia: ¿De qué sujeto estamos hablando cuando hacemos alusión al profesor, al alumno, al adulto o al maestro?

La anécdota argumental de ¿Dónde está la casa de mi amigo?, extremadamente mínima como siempre en el cine del iraní -recuérdense trabajos precedentes como Pan y callejuela o La hora del recreo-, describe la pequeña odisea, recorriendo los ignotos caminos y callejones de un pueblo vecino al suyo, vivida por un niño de ocho años -Ahmed-y su intento de devolver el cuaderno de deberes que ha cogido por equivocación a su compañero de banco. Esta sencilla premisa, sin embargo, se ve enriquecida y adquiere un valor emotivo añadido cuando Ahmed y el espectador saben que de no entregar el cuaderno a tiempo, su amigo no podrá presentar los deberes hechos al día siguiente en clase, será duramente amonestado por el maestro y, probablemente, sea expulsado del colegio al acumular ya varias faltas de este tipo, tal es la amenaza del profesor. Ahmed, gracias a su obstinada actitud, deberá superar una y mil veces la incomprensión de los adultos que encuentra a su paso -unos adultos que, paradójicamente, repiten incansablemente la necesidad que tiene el niño de adquirir responsabilidad y madurez, pero que demuestran al mismo tiempo esa misma falta de responsabilidad en ellos mismos-, remarcando de nuevo la recurrente insistencia 
con la que el realizador iraní vuelve a hablarnos del enorme poder que reside en la voluntad de todo ser humano. Así, el personaje principal -al igual que tantos otros protagonistas de otras tantas obras de Kiarostami-, no se dará por vencido en la conquista de su propósito aún cuando todas las situaciones que se le presenten sean adversas y el objetivo parezca, a cada minuto que pasa, prácticamente inalcanzable. (Tomado de: www.miradas.net/0204/estudios/2004/08_losochenta/ dondeestalacasademiamigo.html).

Varios hallazgos espinosos: el tema de la crisis de autoridad del maestro; la relación escuela-escritura; los desplazamientos o la relación disciplina-tiempo-espacio; dichas movilidades ponen en suspenso la noción de infancia a partir de diferentes contrastaciones: un sujeto sin estatus de reconocimiento; un sujeto que tiene como única tarea solo formarse: condición que reivindica permanentemente el maestro de la película y un sujeto carente. Aquí convendría realizar la revisión de ejemplos recuperados en la tradición de la Comunidad de los Religiosos Terciarios Capuchinos, cuando propusieron la pedagogía reeducativa ${ }^{2}$, a partir de la cual se hicieron diversas reflexiones, para asumir el cuidado de los niños y en especial de los carentes.

Los instrumentos que le dan existencia a la escuela igualmente se contemplan. Esa mirada fija frente a ella a partir de la relación: espacio-maestro-enseñanza-alumno, Kiarostami la desnuda mostrando también las trampas que en su interior se gestan: a) la noción de maestro, el que se construye en la escuela, además portador de un saber cuya esencia de validez se sitúa allí mismo, frente a otras como la que emana el adulto o el carpintero; b) la película hace emerger una crítica a varias prácticas de la escuela: - c) el uso de ese histórico registrador Ilamado cuaderno como referente -en su contenido- del saber que esta transmite consuetudinariamente a través de ella misma (la escuela). Ello, lo ridiculiza en forma particular, usando el

2 Esta centra su preocupación en el análisis, diagnóstico e intervención de los problemas que se presentan en el proceso de socialización, constituyendo ello, el marco de referencia para la definición del campo de intervención del pedagogo reeducador: incluye todos aquellos contextos en los cuales se manifiestan o atienden estos problemas: la institución educativa, la calle, o los centros de intervención especializados - centros de atención a farmacodependientes, a niños y adolescentes infractores y contraventores de la ley, a niños y adolescentes en situación de abandono o situación irregular, entre otros (Ochoa, 1999). 
método de la trampa realizada en el cuaderno por un niño al hacerle -reivindicando el valor del respeto y la solidaridad- la tarea al amigo; $y$ sublima dicha crítica mostrando una flor ubicada en el interior del cuaderno del mismo, regalo este que ha guardado para su compañerito; tal recurso a la postre para mostrar que este -el cuaderno- igualmente puede cumplir otras funciones. Allí, a partir de tal postura, cuestiona la validez del cuaderno, de la libreta de apuntes como documento que no enuncia, que no convoca, el cual ha sido revisado eternamente en el interior de la escuela, pero que no necesariamente deja huellas fuertes en el aprendizaje.

Ahora, allí la didáctica a manera de elemento que contempla el método pone en evidencia un escenario de aprendizaje construído a partir de varios referentes: la autoridad, el espacio escolar, único espacio privilegiado de aprendizaje, la repetición a la manera de único camino para aprender, reforzada desde el consejo del maestro.

Surge entonces un interrogante en la perspectiva de Kiarostami: ¿quién es el protagonista: la mirada o el niño? Esto, dada la imborrable imagen de un menor eliminado simbólicamente: un alumno que nadie escucha, un pequeño que no ven, un infante que por el referente de nadie pasa como sujeto.

Mariano Narodowski (1995) al respecto y en particular en cuanto al sujeto niño, pone de presente varios aspectos, para construir un referente histórico que examine su aparición -del niño- como sujeto, pero también desde la referenciación cognitiva y la emergencia del cuerpo de él en la escuela.

De otro lado nos encontramos seguidamente con El niño salvaje:

El 18 de enero de 1800, un niño desnudo, con la cara y las manos llenas de cicatrices, apareció en las afueras de Saint-Sernin en la escasamente poblada provincia de Aveyron en la parte sur central de Francia. El chico, que solo medía 4 pies y medio de estatura $(1,35 \mathrm{~m}$, aprox.) pero aparentaba tener 12 años, había sido visto varias veces durante los dos años y medio anteriores, trepando los árboles, corriendo en cuatro pies, bebiendo en los arroyos y buscando afanosamente bellotas y raíces. Había sido capturado dos veces, pero había escapado. Entonces, en el inusualmente frío invierno de 1799-1800, comenzó a aparecer en las granjas en busca de alimento. Cuando el muchacho de ojos oscuros llegó a Saint-Sernin, no habló ni respondió para hacerse entender, pero reaccionaba de inmediato ante 
el sonido de las ramas al quebrarse o ante el ladrido de los perros. Rechazaba los alimentos cocidos, prefería las patatas crudas que lanzaba al fuego y recuperaba rápidamente con sus manos desnudas, devorándolas cuando todavía quemaban. Como un animal acostumbrado a vivir en la selva, el chico parecía insensible al frío y al calor extremos, y rasgaba la ropa que la gente trataba de ponerle. Parecía evidente que había perdido a sus padres desde muy pequeño o lo habían abandonado, pero de esto hacía tanto tiempo que era imposible saberlo. Durante un tiempo, el muchacho apareció como un fenómeno intelectual y social, cuando una nueva perspectiva científica estaba comenzando a remplazar la especulación mística. Los filósofos debatían sobre cuestiones como la naturaleza esencial de los seres humanos, preguntas que durante los dos siglos siguientes se convirtieron en fundamento del estudio del desarrollo del niño. ¿Son innatas o adquiridas las cualidades, el comportamiento y las ideas que definen a los seres humanos? ¿Cuál es el efecto del contacto social durante los años de formación, y se puede superar su carencia? Un estudio cuidadosamente documentado de un niño que había crecido en aislamiento podría proporcionar evidencia del impacto relativo de la "naturaleza" (las características innatas de un niño) y la "crianza" (educación familiar, escolar y otros factores de influencia social). Víctor, nombre que se le dio al niño, fue enviado a una escuela para niños sordomudos en París [...]. (Tomado de: http://www.maestrosdelcine. galeon.com/biotruffaut.html).

De la misma manera en El niño salvaje el desenlace no escapa al análisis que se viene presentando en relación con el tipo de sujeto del cual hablamos, en tanto claramente el papel del maestro queda un poco en la cuerda floja, en entredicho o en suspenso dado que en el film es precisamente la señora Guerin -que no tiene el estatus de maestra-quien en últimas le indica el método al doctor; es decir, por ser este último el maestro, no es suficiente para tener la verdad. La película pone en escena una realidad que penetra el aprendizaje, la escuela y la educación sin estar en ella, pues muestra la posibilidad de pensar diferentes órdenes de aprendizaje distintos a lo establecido a la manera 
de elementos claves de aporte y desarrollo social, a partir de enunciar un sujeto que construye su hábitat en un espacio donde las relaciones están dadas por una singularidad: la selva, un mundo salvaje; vale decir, aquel donde los procesos de socialización dados no corresponden a aquellos que han sido asignados a ciertas instituciones: la familia $o$ la escuela, ello en el marco de un pensamiento occidental.

Aquí una advertencia es válida, pues la mirada que el medioevo le había asignado a la vida, a manera de un estereotipo centrado en una creación teológica de orden perfecto, va a contrastar con lo que pudiera esperar de la persona, de un individuo o del sujeto, la modernidad, aquel dotado de una razón, en esencia superior, centrada en unas formas de operacionalización y cognición, en las cuales la lógica como forma de pensar y argumentar posiblemente no es pertinente someterla a discusión.

François Truffaut, director de la película, hace uso de una práctica denominada diagnóstico: 11 años; piel fina oscura; ojos negros, pestañas largas, dentición normal; estatura 1,39 y un olfato que parece el más desarrollado, para mostrar cómo ello no siempre dice, o mejor, no es suficiente para expresar o dar cuenta de la configuración del raciocinio mental, y precisamente si bien es cierto el niño salvaje tiene desarrollo superior en uno de los sentidos -el olfato- es no corresponde a aquel sentido que social e históricamente haya registrado el mayor estatus como la visión, el oído o el habla.

Simbólicamente, la película recupera un estadio en el desarrollo de la humanidad, dejado atrás: la bipedestación y lo triangula con un argumento a partir del cual la sociedad ha construido el orden de los sentidos, es decir, lo que Kant va a llamar las facultades, correspondiendo en expresión numérica a cinco, administradas desde el cuerpo: oído - escuchar ${ }^{3}$, olfato - oler, vista - ver, gusto - saborear, tacto - tocar. Estos y sumados a una cualidad de los seres humanos, el habla, le dan sentido a varias particularidades de la infancia.

Visto así, las dinámicas o formas de construcción cognitiva y en su extensión el aprendizaje, el cual será "alimentado" entre otros en la familia y la escuela por ejemplo, se han explicado a partir de esa quíntuple y armónica sensorialidad: por tanto la anomia, lo diferente o en su expresión más general, lo distinto, resulta excluido, pues corresponde a no tener los cinco sentidos.

3 Frente a ello, y a manera de dato particular debe recordarse el proyecto higieniesta cuyo tránsito se hace entre finales del siglo XIX colombiano e inicios del XX; en las investigaciones de la profesora Estela Restrepo Zea, encontró por ejemplo que los sordos solía mirárseles como patología, asimilados a algo malo, por tanto eran llevados a la cárcel, pues el no atender, se asumía a la manera de cierta desobediencia. De esta autora véase "Cuerpos alterados por el saber médico. El caso de la higiene escolar en Colombia (18301900)". 


\section{El tablero puesto en sospecha: Pizarras}

El film muestra a un grupo de profesores que con una pizarra al hombro, recorren las montañas kurdas, en la frontera entre Irán e Iraq, a la búsqueda de alumnos. La lucha diaria por la supervivencia no deja a la población ni tiempo ni fuerzas para aprender. Dos profesores, Said y Reboir, se separan del grupo: Reboir encuentra unos niños dedicados al contrabando de objetos robados; Said se une a un grupo de ancianos kurdos que, antes de morir, desean volver a ver la tierra donde nacieron, en territorio iraquí. La guerra se mantiene siempre en un segundo plano, pero está omnipresente en el constante ruido de las ametralladoras. (Tomado de: Sinopsis realizada por Gonzalo de Lucas).

En ese seguir ahondando en la mirada al sujeto, la película Pizarras proporciona una condición sui géneris por un conjunto de figuras enigmáticas o si se quiere problemáticas: maestros errantes o en desplazamiento, sin lugar estable; la reflexión sobre si el "saber se ofrece"; otros usos de la educación y las promesas del saber.

La película muestra un interrogante que deja perpleja la función, el lugar, el oficio, por ejemplo, del maestro, pues lo muestra de tal manera que ante esa realidad de ambigüedad, cuestionamientos como el siguiente tienen pertinencia: ¿quién necesita un maestro? Visto así seguimos asistiendo a un momento donde las preguntas frente a la educación, a lo pedagógico, a la escuela y a la sociedad, cada vez generan nuevos interrogantes: ¿La relación escuela-sociedad cómo se da en los tiempos actuales? ¿La función del maestro debe reinventarse? ¿Cuáles son las lógicas de cambio contemporáneas que permean la institucionalidad educativa? ¿Cuáles son los sucesos del afuera de la escuela, que a ella misma la modifican, es decir, la interpelan? O por el contrario, ¿todos aquellos elementos con los cuales hemos vigorizado el papel y/o la función de la escuela, corresponden fundamentalmente más bien a un imaginario en el orden de lo utópico, que a una realidad de la misma? 


\section{La Ola: o la escuela del riesgo}

La vida cotidiana de la escuela como un espacio en el cual se construyen diversas dinámicas que interceptan múltiples órdenes, está de nuevo presente:

En California, EE.UU., en el año de 1967, el profesor Ron Jones realizó un experimento psicológico con sus alumnos basándose en el origen del nazismo y su fanatismo, esto lo hizo famoso. En 1981, Morton Rhue, inspirado en este episodio escribió La Ola. Y sobre estos dos hechos de la vida real, el director Dennis Gansel (Napola) filmó la película homónima a la novela con la actuación del actor alemán Jürgen Vogel, que representa con el nombre de Rainer al citado profesor. La cinta nos muestra la facilidad que puede tener un líder hábil para manejar la psicología de las masas especialmente si se trata de jóvenes a quienes les sobra entusiasmo y energía cuando se unifican a través de un ideal y crean una fuerza en disciplina, acción, pertenencia, orgullo $y$ comunicación plena de actividad. Desde ese punto de vista un movimiento ideológico puede convertirse en algo incontrolable. (Tomado de: www.cinevistablog. com/colaboradores/José Ubillus).

Otro sujeto aparece: la idea de adolescencia... Juventud: a diferencia de la noción de infancia que emergía en las anteriores películas, en La Ola se introduce la perspectiva de un: adolescente o joven que pese a la dinámica inicial de la película -colectivo en crisis-, cumple un papel fundamental: le hace la apertura a un sujeto en formación, en construcción, etc.

En este film conviene explicitar los resultados, diciendo además que el cambio la revolución, gestada a partir de la propuesta hecha por el maestro sí tiene un rasgo movilizador. Ello se puede corroborar en el ejercicio de escritura propuesto por el docente... Veámos algunos resultados -testimonios de estudiantesen la experiencia de esa semana de La Ola:

Siempre he tenido todo lo que quería: dinero, ropa; pero lo que más tenía era aburrimiento... Pero estos últimos días han sido muy entretenidos, ya no se trata de saber quién es la mejor, la más bonita o la de más éxito... La Ola 
nos ha hecho a todos iguales, la religión, la procedencia y el entorno social ya no tiene ninguna importancia; todos pertenecemos a un movimiento, La Ola nos da un nuevo significado, ideales que merece la pena apoyar... Antes solía machacar a otros, cuando pienso sobre ello me parece algo muy anarquista; es mucho mejor comprometerse con algo, si uno puede confiar en los demás conseguiremos más cosas, por ello estoy dispuesto a sacrificarme. (Tomado de los diálogos de la película).

A partir de los desenlaces del film, ¿cuál es el límite entonces de ese rasgo movilizador que construye el maestro, si es que lo genera? ¿En qué momento la escuela quedó incomprendida para pasar a ser destruida, o mejor deconstruida, así sea en el campo de lo simbólico? ¿La figura del maestro como símbolo, modelo a seguir, personaje a imitar, ¿qué enuncia en los tiempos actuales? ¿Cuáles son las condiciones que hacen posible esa idea riesgosa del maestro como un apóstol que llega hasta autocondenarse? ¿Desde qué y en cuál cuerpo actúa el maestro como profesional de la pedagogía?

Seguidamente, la experiencia con la película La cinta blanca, nos adentra en otra oportunidad hacia la apertura del campo de visión aportando elementos para configurar la relación formación-disciplina.

Aquí se muestra como en un idílico pueblo protestante del norte de Alemania tendrá lugar una serie de acontecimientos misteriosos y brutales, narrados por una voz en off perteneciente al maestro del lugar, un anciano que cuenta la historia "parcialmente, de oídas", y que en la época en que se sitúa la acción cuenta con treinta y muy pocos años. En parte, investigará los sucesos, de modo que el personaje funciona al mismo tiempo como narrador y como artífice del parcial desvelamiento de los misterios (palizas, incendios, accidentes incomprensibles) que sacuden la conciencia de todo el pueblo y amenazan con minar la autoridad de los poderes establecidos. Haneke irá tensando la cuerda lenta pero implacablemente, haciendo malabares una vez más con nuestras expectativas y dejándonos desamparados y exhaustos en la conclusión. (Tomado de: www.cinevistablog.com). 
En el film se pone en emergencia la conjunción de tres niveles de actuación dados por la primera trilogía, propuesta en la gráfica 1.

\section{Gráfica 1. Primera trilogía de análisis}

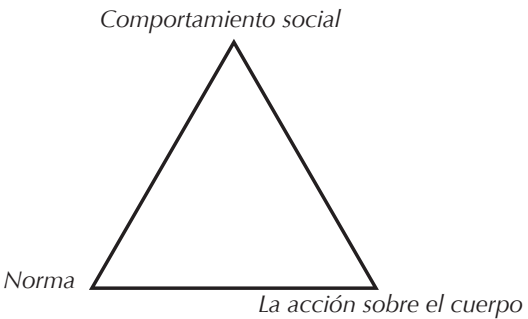

La película, en este caso, nos va a mostrar que todo el sistema de referenciación social-comportamiento social- configura un conjunto de principios o elementos fundantes, los cuales dan origen a una serie de formas de comportarse -normas- que llegan a inspirar diversas prácticas; una de ellas recae sobre el cuerpo: el castigo. Pese a que la experiencia se da en el escenario de una vida aldeana, estos tres elementos se estructuran de manera real y como forma de operar y hacer que la sociedad funcione; dan cuenta de la dinámica en que una determinada organización social se estructura, así no sea el conjunto de los principios que en su interior se construyen, aspecto compartido por todos.

Otra arista del análisis indica que es ineludible en estas narraciones Ilevadas a la pantalla grande poner de presente la emergencia del cuerpo, un tema que está merodeando, volteando, interpelando tales historias. En ese sentido aquí lo convocamos nuevamente para ampliar las consideraciones sobre la triple interacción antes descrita: cuerpo/miradas/poder, igualmente para hacernos la pregunta sobre ¿cómo, a lo largo de la historia y en el marco de la educación en general o mejor específicamente de la escuela, se ha configurado la noción de cuerpo infantil o más adelante de cuerpo juvenil?

Ese cuerpo del niño, del menor, del infante, el cuerpo escolar, adolescente o en su prolongación, el cuerpo joven, produce la encarnación de la denominación explícita de un sujeto que: es formado; está en riesgo (en especial por los resultados del raciocinio o de las acciones instintivas de un cuerpo mayor, vale decir de los adultos, quienes toman decisiones); es negado (a propósito de varias películas anteriores: ¿Dónde está la casa de mi amigo? y Pizarras); es castigado y abusado.

En consecuencia, igualmente el papel de quien enseña sigue latente; aquí en La cinta blanca, la cuidadora Eva -niñera de los gemelos, hijos del barón- símbolo de la figura de maestra, vuelve y sitúa la pregunta problematizando "el papel y/o la función del maestro"4; y pone en evidencia también la discusión sobre las posibilidades de su acción o su actuación.

Con Foucault tendríamos que preguntarnos ¿cómo se dan enton-

4 Para tener una comprensión que amplíe el campo de visión puede resultar interesante rastrear los trabajos de Martínez Boom (1984, 1986). 
ces en dicha realidad las formas de producir subjetividad, mediadas por el saber o la disciplina y agenciadas a partir del poder?

Otro elemento que resulta de interés es la manera en que el film confronta las dinámicas del fascismo de la época, pero haciendo un uso irónico de la moral, se pone en la palestra de la crítica a partir de la forma de recrear la subjetividad desde: la mujer, los hombres o, si se quiere, las infancias.

En la perspectiva foucaultiana cabe recordar cómo la dupla vigilancia-castigo en su proceso de transformación va a visibilizar que cuando en las técnicas de control se agudizan las prácticas de castigo, aparece la vigilancia, variante a partir de la cual el análisis se complejiza robusteciéndose.

A partir de lo anterior, la séptima experiencia a través de la película Doce monos muestra las formas de control que establecen la reflexión ciencia-humanidad-ficción, permitiendo ello plantearse diversas perspectivas frente a: la ciencia; la condición humana; la posibilidad de pensar otras dimensiones de lo social; la ficción permite construir una aventura que quiebra el tiempo y lo vuelve ficción misma; los sistemas de verdad (el caso de la génesis de los virus) y el tiempo como sistema de forma continua, lineal, irreversible, etc.; disciplinas que se erigen en la lógica de estatus de verdad (psiquiatría) o la noción de final, inspirada en la visión apocalíptica que recrea el film.

Aquí, James Cole (Bruce Willis) es un criminal convicto que vive en un siniestro futuro posapocalíptico en Filadelfia. Entre 1996 y 1997, la superficie de la Tierra había sido contaminada con un virus tan poderoso que obligó a la población superviviente a vivir bajo el suelo. Con el fin de ganar una indulgencia, Cole solicita a los científicos ser enviado a peligrosas misiones al pasado para recolectar información sobre el virus, supuestamente liberado por una organización terrorista conocida como el Ejército de los Doce Monos. En lo posible, se le pide que extraiga muestras de aquel agente patógeno para poder descubrir una cura. A lo largo del filme, Cole experimenta sueños recurrentes que envuelven una persecución y un disparo en un aeropuerto. En su primera misión, Cole llega a Baltimore en 1990, no en 1996 como estaba previsto. Es arrestado e internado en un hospital psiquiátrico debido al diagnóstico de la doctora Kathryn Railly (Madeleine Stowe) Allí conoce a Jeffrey Goines (Brad Pitt), un 
paciente anticonsumista obsesionado con los derechos de los animales. Cole intenta en vano dejar un mensaje de voz en un número monitoreado por los científicos del futuro. Luego de una fallida tentativa de fuga...

Conviene entonces retomar varios postulados que Baudrillard ${ }^{5}$ elaboró en relación con la muerte del signo o los conceptos de simulacro y simulación, siendo ellos aspectos neurales para abordar dos asuntos: la noción de cyborg, a la manera del híbrido supremo de hombre y máquina y la percepción de cuerpo encarnado en la propuesta recreada en la película, pero no sin precisar un interrogante crucial: ¿las culturas producen los cuerpos que necesitan?

Más adelante cuando logramos ingresar en la propuesta de Nosferatu, allí se recupera la tarea de apertura en el campo de visión, al permitirle a su argumento mirar cuatro dimensiones, que de ser examinadas con rigor aportan elementos preponderantes.

Nosferatu construye un argumento profundamente tenso dada su condición de poner en sospecha diversas prácticas y discursos catapultados bajo nominaciones universales y aparentemente irreversibles: vida/muerte-salud/enfermedad-magia-creencia/conocimiento cientí-

5 Sobre estos tópicos puede consultarse BaudriIlard (1974, 1990, 1993). fico. Podemos preguntarnos aquí entonces a partir de diversas formas: ¿De qué manera el discurso de la higiene en tiempos atrás se produjo en términos del concepto salud vs. enfermedad como función biopolíti$\mathrm{ca}^{6}$ ? ¿Qué lugar ocupó la salud-enfermedad como pedagogía social y también a manera de gobierno de la población? ¿Qué tipo de relaciones se establecieron entre el saber médico y la pedagogía en las primeras décadas del siglo XX? ¿Fue la escuela el único lugar que dio paso al proyecto pedagógico higienista? $\mathrm{Y}$ complementarios a este interrogante, ¿cuál es el papel de los manuales de instrucción y los de urbanidad en esta realidad?

Nosferatu, eine Symphonie des Grauens (Nosferatu, una sinfonía del horror), conocida en castellano como Nosferatu y Nosferatu el vampiro (España), es una película muda de 1922 dirigida por Friedrich Wilhelm Murnau. Thomas Hutter es un empleado de una compañía inmobiliaria en Wismark, Alemania, que vive tranquilamente con su esposa. Un día su jefe, Knock, recibe una extraña carta escrita con símbolos que reconoce como del Conde Orlok, quien desea comprar una 
casa en Wismark. Knock envía a Hutter a los Cárpatos para concretar con el Conde Orlok la venta de la casa. Hutter deja a su esposa Ellen en casa de su amigo Harding y se embarca. Cerca de su destino, Hutter se hospeda en una posada en la cual menciona que se dirige a ver al Conde Orlok. Todos los presentes se aterran de solo escuchar el nombre del Conde y tratan de convencerlo de no ir. Hutter encuentra en su cuarto un libro sobre vampiros el cual tilda de supersticioso, pero que mantiene consigo como material de lectura. Al día siguiente parte hacia el castillo. Un cochero contratado lo lleva hasta el bosque que rodea el castillo, pero se niega a cruzar el puente que cruza hacia este. Al rato, un cochero misterioso se identifica como cochero del Conde.

El ciclo de los nueve momentos cierra con The Matrix, pero a partir de allí se abre con gran fuerza el campo de visión.

Es una película de ciencia ficción escrita. En ella Neo descubre que el mundo en el que creía vivir no es más que una simulación virtual a la que se encuentra conectado mediante un cable enchufado en su cerebro. Los miles de millones de personas que viven (conectadas) a su alrededor, están siendo cultivadas del mismo modo para poder dar energía a las máquinas. Esta ilusión colectiva (o simulación interactiva) es conocida como The Matrix -la matriz-. El grupo de rebeldes del mundo real liderados por Morfeo, rescata a Neo de la cosecha de personas donde se encontraba preso. Una vez liberado y "a salvo", Morfeo le explica en qué consiste la realidad: se encuentran cerca del año 2199 y la humanidad está esclavizada por las máquinas, que tras el desarrollo de la inteligencia artificial se rebelaron contra su creador, el hombre. La revolución desembocó en una gran guerra por la supervivencia de ambos contendientes, esta a su vez, desembocó en el deterioro del medio ambiente haciéndolo insostenible para hombre y máquina.

Con ella nos damos cuenta que el hombre en su recorrido hacia la "conquista" por el avance tecnológico o la construcción de uno de los fundamentos del paradigma del de- 
sarrollo -después de mediados del siglo pasado- fantaseó con varias metáforas constructoras de realidad:

a) la metáfora de la velocidad y por ejemplo en el uso del mundo de la física (Einstein), avivó el pensamiento científico. Paul Virilio (1997a , b), quiérase o no, invitó a las ciencias sociales a pensar esta metáfora; b) la metáfora del poder único en configuración de Imperio (Negri y Hard, 2005); c) la metáfora del disciplinamiento como aparente forma de organización (Foucault) y a la cual se suma la del control y la máquina abstracta "subyacente" (Deleuze, 2006), y d) la metáfora de la inteligencia como opción extrapolable a la máquina (IA, inteligencia artificial)... ¿ ¿será que con esta última se instala una concepción cibernética de la pedagogía?

Ellas, las metáforas, se entrelazan, permitiendo los resultados de estos cruces generar herramientas con las cuales se puede intentar rastrear Matrix. En ese sentido las ideas de hibridación, mimetización y de sincretismo entre otras, como nociones conceptuales, siendo esta última heredada de las ciencias sociales para explicar el fenómeno de entrecruzamiento, o si se quiere interconexión, señalan posibilidades valiosas en el campo exclusivamente del comportamiento social y de ámbitos como el de la cultura. Pero precisamente en el caso de la Matrix, la humanidad que tiene como sujeto

7 Sobre esta consideración viene realizando una reflexión Soto (2009). central al hombre y otras formas de vida, animal, vegetal, etc., es interpelada, pues pareciera darse la emergencia de una fuerza, una energía, una potencia la cual pone en riesgo los controles que la razón misma fue capaz de dirigir.

Dadas tales consideraciones podemos decir pues que Doce Monos, aunada a la octava película Nosferatu y la novena The Matrix, en esta experiencia dan forma a la triada: ciencia, tecnología y salud como lo muestra la gráfica 2, la cual pone en escena la segunda trilogía.

Gráfica 2. Segunda trilogía de análisis

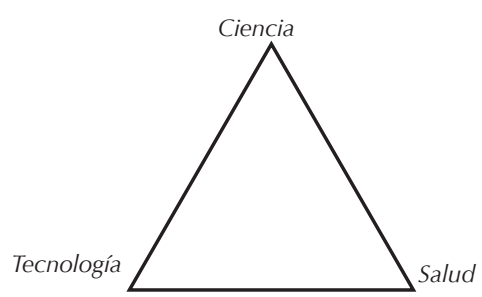

En tal sentido, tanto la primera trilogía al igual que segunda, dan sentido a un conjunto de elementos a partir de los cuales se edifica una tercera trilogía donde se pone en juego la pedagogía y la escuela, y ello se propone como recurso para abordar teórica y metodológicamente el objeto de investigación.

Gráfica 3. Tercera figura de análisis

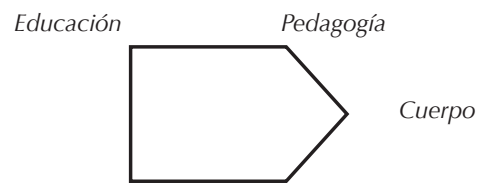

Institución educativa 


\section{Para ampliar el campo de visión: las posibilidades en la investigación}

En ese tránsito de ampliar el campo de visión, el cine como experiencia sensible y vital a partir de los nueve encuentros empujó la reflexión a otros niveles. Tal vez resulte aún reducido el desarrollo que frente a este tópico se presente aquí, pero puede ser útil señalar lo siguiente: el abordaje del objeto de estudio el cual se interpeló a partir del cine implicaría entre otros iniciar un análisis que se distancie de problematizar las reflexiones sobre el cuerpo exclusivamente a manera de entidad física, anatómica o forma explícita, para avanzar a partir de la valoración de documentos -hallazgos empíricos- y dadas las condiciones de posibilidad -si se quiere disciplinares/teóricas- por ejemplo de la sociología, la antropología, la psicología, la educación o la pedagogía, en proponer un conjunto de referentes diferenciales, en la idea de construir una problematización donde partiendo de varios factores o aristas: los discursos de la higiene y la salud; la velocidad a la manera de Virilio (1997a) como dinamizador de estéticas corporales; la publicidad en sentido de argumento construidos a partir del cuerpo y los discursos y prácticas estéticas y del consumo; promuevan un punto de partida distanciado de la opción argumentativa usada en los tiempos actuales, a partir de la diada causa/efecto, entendida esta última como único modo para explicar asuntos de tensión sobre cuerpo ${ }^{8}$, consumos y educación.

Algunas preguntas resultarían necesarias en dicho cometido: ¿Cuáles son los elementos socio-históricos que han construido y producido una noción de cuerpo desde la escuela? ¿Cuál es la corporalidad del maestro en los ámbitos educativos o forma-

8 La contribución de varias disciplinas ya es importante, por ejemplo a partir de las antropologías sobre el cuerpo (Blacking: 1977) y (Le Breton: 1990); una sociología del cuerpo (Berthelot: 1995) y (Shilling: 2003), o una historia del cuerpo (Barrán: 1995) y (Boltansky: 1971) - Tomado de Pedraza Gómez, Zandra - Compiladora (2007). Políticas y estéticas del cuerpo en América Latina. Además para rastrear el tema, puede consultarse Le Breton, David (2004). Antropología del cuerpo y modernidad. Buenos Aires. Nueva Visión; Gómez, Rocío del Socorro y González, Julián (2003). Design: designar/diseñar el cuerpo joven y urbano.; Costa, Pere-Oriol (1996). Tribus urbanas. El ansia de identidad juvenil: entre el culto a la imagen y la autoformación a través de la violencia. BARA, André (1975). La expresión del cuerpo. Buenos Aires. Ediciones Búsqueda y Pedraza, Sandra (1998). La cultura somática de la modernidad: historia y antropología del cuerpo en Colombia. También sobre el tema puede consultarse la Revista Colombiana de Antropología No 45 de Enero - Junio de 2009, la cual aborda entre otros los siguientes ejes: cuerpo, subjetividad y maternidad; cuerpos en construcción: intervenciones y resistencias y cuerpo, salud y ritual. 
tivos? A propósito de la infancia y la juventud, ¿cuál es el cuerpo que emerge a partir de las películas y cuáles son las formas de subjetivación que históricamente se han producido?

\section{Referencias}

Álvarez G, A. (1995). ...y la escuela se hizo necesaria: en busca del sentido actual de la escuela. Bogotá: Editorial Magisterio.

Antonioni, M. (1966). Blow Up. Película.

Banyai, I. (1996). Zoom. México: Fondo de Cultura Económica.

Banyai, I. (1999). Re-zoom. México: Fondo de Cultura Económica.

Baudrillard, J. (1974). Critica de la economía política del signo. México: Siglo XXI Editores.

Baudrillard, J. (1990). De la seducción. México: Editorial Rei.

Baudrillard, J. (1993). Cultura y simulacro. Barcelona: Kairós.

Cabrera I., G. (1997). Cine o sardina. Madrid: Alfaguara.

Cantet, L. (2008). La Clase. Película.

Deleuze, G. (2006). Post-scriptum sobre las sociedades de control. Rev. Polis., 5(13), .

Foucault, M. (2007). Seguridad, territorio, población. Curso en el Collége de Francia (1977 1978). México: Fondo de Cultura Económica.

Foucault, M. (2009). Nacimiento de la biopolítica: curso del College de France (1978-1979). Buenos Aires: Fondo de Cultura Económica.
Gansel, D. (2008). La Ola. Película.

Gilliam, T. (1995). Doce monos. Película.

Haneke, M. (2009). La cinta blanca. Película.

Kiarostami, A. (1987). ¿Dónde está la casa de mi amigo? Película.

López, M. (1999). Grandes ejes temáticos de la pedagogía reeducativa. Grupo Impresor Ltda. Medellín. 1999.

Makhamalbaf, S. (2000). Pizarras. Película.

Martínez B., A. (1984). El maestro y la instrucción pública en el Nuevo Reino de Granada 1767 - 1809. En: Dos estudios sobre la educación en la Colonia. Bogotá: Universidad Pedagógica Nacional. Centro de Investigaciones CIUP.

Martínez B., A. (1986). Escuela, maestro y métodos en la sociedad colonial. Bogotá: Universidad Pedagógica Nacional. Centro de Investigaciones CIUP.

Murnau, F.W. (1992). Nosferatu. Película.

Narodowski, M. (1995). Infancia y poder. Buenos Aires: Aique.

Negri, A. y Hardt, M. (2005). Imperio. Madrid: Paidós.

Ochoa, M. (1999). Hacia la resignificación de la reeducación en el programa de Licenciatura en Pedagogía Reeducativa. Medellín: Fundación Universitaria Luis Amigó (mimeo).

Quiceno C., H. (1984). Historia de la práctica pedagógica en Colombia. Siglo XX (1903 - 1927). 